\title{
ARTIGO
}

\section{Informação: fenômeno e objeto de estudo da sociedade contemporânea}

\author{
Information: phenomenon and research \\ subject in the contemporary society
}

Nair Yumiko KOBASHI

Maria de Fátima Gonçalves Moreira TÁLAMO²

\section{R E S U M O}

O estudo da informação assume importância primordial na cultura contemporânea, sendo tema desenvolvido por várias áreas do conhecimento. Cada disciplina deve, no entanto, identificar na informação o seu objeto específico, para que uma atividade compreensiva sobre o assunto substitua a explicação mecânica e funcionalista, largamente difundida, que não raro introduziu mais dúvidas e imprecisões do que soluções. É objetivo deste artigo discutir tanto o papel da Ciência da Informação no contexto das disciplinas que estão se constituindo, quanto a sua relevância sócio-política e econômica. Enfatiza-se a importância da elaboração conceitual para o entendimento do seu objeto e para a proposição de alternativas compreensivas do fenômeno. Conclui-se que a compreensão não se dá na amplitude do fenômeno geral, que está presente em todos os contextos disciplinares; ao contrário, ela requer a delimitação do contexto específico no qual a informação está sendo vista como valor e produtora de valor. A partir daí, os traços simplificados e fragmentados que a caracterizam serão consecutivamente analisados e substituídos através de uma abordagem que considere a complexidade da informação.

Palavras-chave: ciência da informação, estudos de informação, conceito de informação.

\footnotetext{
${ }^{1}$ Doutora em Ciências, Docente, ECA/USP. Coordenadora, Programa de Pós-Graduação em Ciência da Informação, Pontifícia Universidade Católica de Campinas. Praça da Imaculada, 105, Vila Santa Odila, 13045-901, Campinas, SP, Brasil. Correspondência para/Correspondence to: N.Y. Kobashi. E-mail: nykobash@puc-campinas.edu.br

2 Doutora em Ciências da Comunicação, ECA/USP. Docente, Programa de Pós-Graduação em Ciência da Informação, Pontifícia Universidade Católica de Campinas.
} 


\section{A B S T R A C T}

The information study has fundamental importance in contemporary culture, being a subject in several areas of knowledge. However, each discipline must identify in this phenomenon its specific subject, so that a comprehensive activity about it come to replace the largely accepted mechanical and functionalist explanation, which often has brought about more inaccuracies and doubts than solutions. This article aims at discussing not only the role of Information Science in the context of other disciplines that are being constituted, but also, its social-political and economic relevance. It emphasizes the importance of the concept elaboration, for a better understanding of its subject and for proposing comprehensive alternatives of the phenomenon. It concludes that comprehension does not take place at the ample level of the general phenomenon, which is present in all fields of knowledge. Instead, comprehension requires delimitation of the context in which a piece of information is being perceived as a value and as a producer of value. Then, the simplified and fragmented aspects that characterize it will be analyzed and consecutively replaced, through a method that considers the information complexities.

Key words: information science, information studies, information concept.

\section{N T R O D U Ç Ã O}

Na sociedade contemporânea, caracterizada pelos fluxos da informação em escala global, o direito à informação assume papel fundamental, não só por constituir-se crescentemente como direito elementar, mas também porque encontra-se integrado à base da ação na esfera privada ou pública. Parece que, especificamente, o acesso à informação impõe-se como um direito global e globalizante em relação aos demais. A expressão "cidadania planetária" dá conta desse aspecto e não é de se estranhar, portanto, que as suas várias ocorrências sinalizem questões relativas à integração da oferta, do acesso e do uso da informação no cotidiano.

Em face do afirmado, o estudo da informação, da sua produção, circulação e consumo, assume importância primordial, sendo desenvolvido por várias áreas do conhecimento. Assim, ao lado da importância da informação se reconhece também a complexidade de abordála. Muitas são as disciplinas que a focam e, cada uma deve nela, identificar o seu objeto específico para que uma atividade compreensiva sobre o assunto substitua a explicação mecânica e funcionalista largamente difundida no campo, que não raro introduziram mais dúvidas e imprecisões do que soluções. Talvez poucos se lembrem da obra coletiva organizada por Guéroult, em 1965, na qual pesquisadores de áreas tão diversas como a Física, a Matemática, a Biologia, a História, a Economia, discutiram o conceito no contexto da ciência contemporânea. É objetivo deste artigo discutir o papel da Ciência da Informação no contexto das disciplinas que estão se constituindo associadas à relevância sociopolítico-econômica da informação, enfatizandose a importância da elaboração conceitual para o entendimento do seu objeto e para a proposição de alternativas compreensivas do fenômeno.

\section{IN F O RM A ÇÃ O E CIDA D A I A}

A cidadania plena pressupõe necessariamente o exercício de três direitos: os civis, os políticos e os sociais. Esses direitos garantem ao indivíduo participar da sociedade, nela 
integrar-se e nela intervir. Como observa Pinsk e Pinsk (2003, p.10) a cidadania não é um conceito estanque, varia no tempo e no espaço. Isso significa que existe alteração significativa do exercício da cidadania segundo as coordenadas espaço-temporais.

A informação é, de fato, um dos elementos básicos para a inteligibilidade dos processos sejam eles naturais ou culturais. Por isso mesmo, enfrenta-se dificuldade crescente para abordá-la nocionalmente. Sabemos que, dependendo do contexto, haverá uma variação conceitual acentuada, cujos efeitos de sentido, não raro, induzem significados fracamente discriminatórios que distorcem o entendimento das principais questões em jogo. Ao lado da complexidade da informação instala-se a extrema fragilidade do termo. Ambas acabam sendo o grande desafio a ser superado por uma organização mais coerente dos campos de estudo a ela dedicados.

O passo fundamental para propiciar a aludida compreensão é o de explorar os traços característicos da informação na contemporaneidade. É o que faremos a seguir, valendo-nos de um argumento analógico.

A fome mundial tem sido há décadas objeto de discussão e de especulação da mídia, dos órgãos internacionais e governamentais e das associações da sociedade civil. Entre as miríades de posicionamentos frente ao fato, destaca-se aquela que relaciona a fome, não à escassez de alimento, mas à ausência de modos de distribuição adequados. Esta perspectiva impõe, de imediato, a associação do alimento ao bem material, conferindo-Ihe as propriedades inerentes a este universo.

O bem, independentemente de sua natureza material ou simbólica, define-se como um objeto - material ou imaterial - que responde pela satisfação das necessidades físicas e culturais do homem. Por isso os conjuntos de bens integram necessariamente o sistema estruturado pelos seguintes elementos: produ- ção, armazenamento, distribuição, acesso, troca e uso. Nesse sentido, qualquer bem necessário que não participa desse sistema gera carência e desigualdade na sociedade.

Ao integrar o alimento no conjunto dos bens, pode-se afirmar simultaneamente, que o alimento existe e que a sua distribuição é parcial. Afirma-se, portanto, que a fome associa-se a uma distribuição ineficiente do alimento. No entanto, dada a definição de sistema de bem, observa-se que a questão apresenta outras variáveis. De fato, uma vez resolvida a distribuição, nada garante o fluxo de alimentos, à medida que este só pode ser concretizado na troca que envolve moeda de conversão específica. Então, a fome passa a ser interpretada tanto como resultado de fluxo impróprio de alimentos quanto como ausência, falta de acesso, má distribuição da moeda de conversão.

A informação, como o alimento, é um bem. Do mesmo modo que a carência de alimento provoca a fome, a carência da informação provoca a ausência do conhecimento. Observe que foi afirmado carência e não escassez, uma vez que a carência não se encontra, como vimos, em relação de causalidade necessária com a escassez.

Para superar situações de carência e de escassez, a sociedade organiza seus estoques de informação e estabelece estratégias específicas para colocá-los em ação, para transformá-los em fluxo, tendo em vista um único objetivo: que o sujeito os capture, promovendo a ação de conhecer.

Ao contrário do bem material, a informação é um bem simbólico, porque se elabora, organiza e circula no interior da linguagem. Ainda ao contrário do bem material, o uso da informação não a esgota. Mas tanto o bem material como o simbólico necessitam de um elemento de troca. Para se ter a informação, como para se ter o alimento, é preciso uma moeda de conversão sem a qual a informação não se transforma em conhecimento e o alimento não 
se transforma em energia que aplaca a fome. No primeiro caso o elemento de troca é a cognição e o capital cultural e, no segundo, a moeda propriamente dita.

\section{N F O R M A ÇÃ O CO MO O BJETO DE PESQ UISA DA CIÊNCIA D A I N F O R M A Ç Ã O}

A informação - sua natureza, propriedades, produção, circulação e consumo, seja ela massiva ou direcionada para grupos específicos - vem se transformando em objeto de estudo de diversas disciplinas. As Ciências da Comunicação e a Teoria da informação, por exemplo, constituíram-se, em torno delas. É necessário, portanto, explorar os conceitos antes de discutir o estatuto de uma Ciência, a da Informação, que reivindica, tal como as duas anteriores, a informação e o seu fluxo, portanto sua comunicação, como seus objetos legítimos.

Abril (1997) afirma que a Teoria da Informação, de Shannon e Weaver, constituiu-se com objetivos instrumentais: os de obter a máxima economia de tempo, de energia e portanto de recursos financeiros, nos processos de transmissão de informação. A informação aqui é sinal que deve ser submetido a controle, configurando-se como processo energético de codificação e decodificação de sinais, não havendo lugar, nesta teoria, para as questões relativas ao significado das mensagens.

A Teoria da Comunicação opera, no registro contemporâneo, com a dimensão simbólica da interação, com a heterogeneidade dos sujeitos e da cultura. A informação é processo de troca de mensagens que supõe a construção de sentidos. Desse modo, emissão e recepção de informação são atos interdependentes que requerem interpretação para que seja efetiva a comunicação.

Os conceitos de informação, adotados na Teoria da Informação e na Teoria da Comunicação distinguem-se, portanto, pelas questões da significação assumidas por esta última. É, este aspecto que coloca dificuldades para a mensuração da informação através de métodos estatísticos, como ingenuamente se procurou fazer no processo de constituição da Ciência da Informação, nas décadas de 50 e 60 do século passado. A problemática da informação, na Ciência da informação, aproxima-a do campo teórico da Teoria da Comunicação, precisamente porque ambas operam com o sentido. Pode-se afirmar, nessa perspectiva, que a informação documentada é objeto material da Ciência da Informação, enquanto os processos de sua estruturação para o fluxo e a recepção são seu objeto formal.

A ampliação dos campos que se interessam pela informação parece relacionar-se, igualmente, ao fato de ela se configurar como recurso estratégico não apenas para a organização e o controle sociais, mas principalmente para a produção de bens. Como observa Burke:

\begin{abstract}
Estamos imersos hoje, ao menos segundo alguns sociólogos, em uma "sociedade do conhecimento" ou "sociedade da informação", dominada por especialistas e seus métodos científicos. Segundo alguns economistas, vivemos em uma "economia da informação", caracterizada pela expansão das atividades relacionadas com a produção e a difusão do conhecimento. Por outra parte, o conhecimento converteu-se em um problema político de primeira ordem, centrado na questão de se a informação deveria ser pública ou privada, tratada como mercadoria ou bem social (BURKE, 2002, p.11).
\end{abstract}

É este aspecto multifacetado da informação que desafia os que se propõem a discuti-la e a torná-la socialmente apropriável. Nota-se que a discussão sobre sua produção e circulação, 
que vinha sendo abordada dominantemente pela Ciência da Comunicação e da Informação, incorpora-se de forma crescente aos modelos propostos pela Administração e a Informática, em particular a partir dos anos 1990. Nesses contextos, procura-se estabelecer as características do conceito segundo seu alcance operacional: no âmbito dos sistemas de informação gerencial procura-se manipulá-la como instrumento de apoio à gestão; nas modernas teorias organizacionais, informação e conhecimento são ativos que potencializam a competitividade (NONAKA; TAKEUCHI, 1997).

A discussão requer, portanto, delimitar o âmbito no qual a informação é vista como valor e como produtora de valor. Parece adequado vinculá-la a uma formação histórica específica, que recebe denominações variadas: Sociedade da Informação, Sociedade pós-industrial, Sociedade do conhecimento. Independentemente da denominação atribuída, tal formação é, para Abril (1997), simultaneamente, informacional, informada e informativa. É informacional no sentido de incluir aspectos operacionais e técnicos em que a linguagem e o conhecimento são tratados para serem transmitidos à distância, com a neutralização simultânea do espaço e do tempo. É informada na medida em que a produção e a recepção de conhecimentos científicos assumem proporções gigantescas. É informativa por ser sociedade na qual circulam numerosos e variados discursos informativos; o acesso a eles converte-se em valor fundamental indicador de participação política, de cidadania, de identidade.

Nessa mesma perspectiva, Morin afirma que (2002, p.16):

Por detrás do desafio global e do complexo, esconde-se um outro desafio: o da expansão descontrolada do saber. $\mathrm{O}$ crescimento ininterrupto dos conhecimentos constrói uma gigantesca torre de Babel, que murmura linguagens discordantes. A torre nos domina porque não podemos dominar nossos conhecimentos.... O conhecimento só é conhecimento enquanto organização, relacionado com as informações e inserido no contexto destas. As informações constituem parcelas dispersas de saber. Em toda parte, nas ciências, como nas mídias, estamos afogados em informações. O especialista da disciplina mais restrita não chega sequer a tomar conhecimento das informações concernentes a sua área. Cada vez mais, a gigantesca proliferação de conhecimentos escapa ao controle humano.

No campo da Ciência da Informação, área tradicionalmente vinculada ao tratamento e difusão de conteúdos convertidos em informação organizada, observa-se igualmente o deslocamento gradual da perspectiva patrimonialista, que caracterizava, e em larga medida ainda caracteriza as instituições de memória, sejam elas bibliotecas, centros de informação ou arquivos, para as questões informacionais e comunicacionais, promovendo e estimulando sua reformulação teórica. Do que foi dito, pode-se sintetizar os aspectos relevantes da sociedade contemporânea passíveis de integrarem os estudos da informação no âmbito da Ciência da Informação, conforme o que segue:

1. A informação, que antes era tida como estoque a ser preservado e tinha seus estudos calcados unicamente nas formas de registro segundo os parâmetros do conhecimento científico, é tomada agora no seu sentido dinâmico. Nele os processos de circulação assumem importância social, determinando que a distribuição e o acesso à informação sejam tratados como questões sócio-político-econômicas, de natureza pública portanto. A informação não se apresenta mais como uma questão individual, é um problema social.

2. A tecnologia da informação projetou as condições instrumentais para a consolidação do 
aspecto informacional e comunicacional da sociedade contemporânea. Mas, ao mesmo tempo, estabeleceu e disseminou a relação ambígua entre o meio e a mensagem. Decorre dessa ambigüidade a falsa idéia de que a tecnologia não é apenas um instrumento de produção mas uma máquina inteligente. Ao tornar mecânica a produção da informação, esta passa a submeter-se de forma crescente ao processo de mercantilização: fala-se em grande quantidade de informação, afirma-se que, embora seja grande a oferta da informação, a sociedade dispõe de pouco conhecimento. Afinal o que significam, de fato, tais proposições? Seria essa analogia entre informação e mercadoria a mais apropriada para o desenvolvimento de uma interpretação adequada dos fluxos de informação? Semelhante contexto, a nosso ver, apenas favorece a afirmação da quantificação simplista da informação, que a distancia da abordagem comprometida com a sua organização simbólica.

3. A importância da informação e do conhecimento na contemporaneidade vincula-se largamente à relação de pressuposição recíproca que mantêm. De um lado, isto evidencia que a sociedade contemporânea não se caracteriza pela importância, sobejamente reiterada, que atribui à informação e ao conhecimento, importância de resto facilmente atestada em vários outros momentos históricos; e de outro, permite observar que os termos que se encontram originalmente relacionados passam a ter uso sinonímico, isto é, são intercambiáveis em praticamente todos os contextos. Observe-se a expressão usual "sociedade da informação ou sociedade do conhecimento". Este uso sinonímico não só oculta a distinção original dos termos "informação" e "conhecimento", associados respectivamente à natureza social do primeiro e subjetiva do segundo, mas também introduz distorções teóricas no entendimento da relação que mantêm entre si.

A constituição interna - teórica e pragmática - que vem experimentando a Ciência da Informação, como veremos, promove uma forma de abordagem dos três aspectos assinalados, de modo a reverter a formulação simplista da informação que induz uma interpretação equivocada do seu trajeto na sociedade.

\section{A CIÊ NCIA D A I N F O R A C Ã O NO PARA DIG M A A PÓ S-M O DER N IDA DE}

O divórcio entre teoria e prática, discurso e experiência, a fragmentação do campo científico em diferentes especializações, características da ciência moderna, são postos em questão na pós-modernidade. Segundo Harvey, os questionamentos e mudanças subseqüentes "por certo foram afetadas pela perda da fé na inelutabilidade do progresso e pelo crescente incômodo com a fixidez categórica do pensamento iluminista" (HARVEY, 1994, p.37). Nesse contexto, a ciência, a forma por excelência do processo de conhecer da modernidade, aquela que até então mais suscitara confiança e credibilidade, começa a ter suas bases abaladas. Nos anos 1980, os movimentos de refundação de inúmeras disciplinas, tanto no âmbito das ciências ditas exatas, como no das ciências sociais e das humanidades, ao se distanciarem dos princípios da ciência moderna, passam a ser referidas como ciências pós-modernas.

Estabelecer, pois, fronteiras rígidas entre disciplinas é uma impossibilidade assumida no trabalho de construção do conhecimento. Afirma-se a interdisciplinaridade como forma de organizar o trabalho científico, cujas dificuldades, no entanto, são um campo minado. Segundo Barthes (1988, p.99):

O interdisciplinar de que tanto se fala não está em confrontar disciplinas já constituídas das quais, na realidade, nenhuma consente em abandonar-se. Para se fazer interdisciplinaridade, não basta tomar um "assunto" (um tema) e convocar em torno duas ou três ciências. A interdisciplinaridade consiste em criar um 
objeto novo que não pertença a ninguém.

Ao conceito de interdisciplinaridade associa-se, via de regra, o de multidisciplinaridade. Segundo Machado, na multidisciplinaridade “...os interesses próprios de cada disciplina são preservados, conservando-se sua autonomia e seus objetos particulares" (MACHADO, 1995, p.193). Dito de outro modo, não se busca a interação nos níveis metodológico ou de conteúdo, havendo fundamentalmente a justaposição dos vários saberes em um espaço compartilhado. A interdisciplinaridade caracteriza-se, ao contrário, pela "intercomunicação efetiva entre disciplinas" (MACHADO, 1995, p.194). Trata-se, portanto, de um processo dialógico que requer interpenetração metodológica e uma (meta)linguagem compartilhada. $O$ conhecimento produzido distingue-se, nessa medida, daquele existente nas disciplinas de origem.

Em texto considerado clássico, Saracevic (1995) afirma que a Ciência da informação se define, como outros campos do conhecimento, pelos problemas a que se dedica e pelos métodos que utiliza para solucioná-los. Três são as suas características fundamentais: a interdisciplinaridade, sua relação necessária com as tecnologias da informação e seu papel na constituição da sociedade da informação. Este último aspecto a define como uma ciência que apresenta forte dimensão social e humana. Semelhante dimensão associa-se à solução dos problemas de acesso à informação gerada e estocada socialmente. Com efeito, a Ciência da Informação preocupa-se com a pesquisa científica e a prática profissional relativas à comunicação, necessidades e uso da informação em contextos sociais, institucionais e individuais. Informação e comunicação são as palavras-chave de sua proposição.

$\mathrm{O}$ ato de informar, na Comunicação em geral, e também na comunicação documentária, supõe a organização prévia da informação em categorias aptas a circular nas várias esferas da sociedade. Considera-se, assim, a presença de um sistema que elabora mensagens (o sistema de informação documentário) e o enunciatário (o usuário) que as recebe e as interpreta. A transferência de informações requer, portanto, a elaboração de mensagens (representações) que propiciem interpretações produtivas. Nesse sentido, informação é fundamentalmente "estrutura significante" capaz de gerar conhecimento (BARRETO, 1994). Evoca-se, assim, a idéia de que a informação é produto de labor humano.

A operação com a informação no campo da Ciência da Informação parece, portanto, requerer a adoção de dois paradigmas, em princípio opostos: a Teoria da informação para lidar com sua dimensão formal (como estrutura e como sinal) e a Teoria da comunicação para dar conta da mensagem e sua recepção (como significado).

Wersig (1993) aponta novos caminhos ao estabelecer como ponto de partida uma crítica radical sobre as questões pretensamente "paradigmáticas", tradicionalmente discutidas no campo. Segundo o autor, a busca de soluções para os problemas da recuperação da informação, em face de sua crescente produção, são questões de superfície que não promovem a constituição de um campo científico. São apenas respostas práticas para problemas sociais concretos. Essa perspectiva, associada de forma dominante à dimensão técnico-profissional, é responsável pelo abandono da reflexão específica sobre as formas da circulação social da informação e do conhecimento. Wersig propõe, desse modo, a discussão da Ciência da Informação no quadro das mudanças do papel do conhecimento na sociedade contemporânea. Quatro aspectos são considerados relevantes nessa discussão: a despersonalização, a fragmentação, a confiabilidade e a racionalização do conhecimento.

A despersonalização do conhecimento associa-se ao desenvolvimento das tecnologias 
da comunicação. Estas últimas ao possibilitarem a comunicação à distância promovem simultaneamente a ausência crescente de contatos pessoais. Os diversos ensaios de personalização, via recursos de interatividade mediados pelas tecnologias da informação, não têm, necessariamente, permitido aos indivíduos superar tal despersonalização. Nesse contexto, Wersig refere-se à confiabilidade do conhecimento. Esta última apoiou-se, durante um longo período, nas possibilidades oferecidas pela observação e experimentação diretas. Atualmente, no entanto, o conhecimento apóia-se na confiança que se pode atribuir aos processos de manipulação de dados por meios tecnológicos.

A fragmentação do conhecimento e sua especialização derivam, em larga medida, da autonomização das esferas de ação, fenômeno também estreitamente associado à racionalização e ao cálculo. A percepção da impossibilidade de aplicar padrões e calcular certos fenômenos promove a busca de novos paradigmas de racionalidade.

O conjunto de características acima exposto fundamenta o paradigma informacional de Wersig: o de que a informação é conhecimento para a ação. Com efeito, na sociedade contemporânea, o comportamento racional demanda conhecimento e o papel da Ciência da Informação é exatamente o de auxiliar pessoas - os atores - que se encontram em situação problemática em relação ao uso do conhecimento.

Essa idéia, no entanto, tem raízes mais antigas. Segundo Burke (2002, p.80): "a reforma das bibliotecas fora incluída na reforma baconiana do ensino empreendida na Inglaterra em meados do século XVII. Segundo John Durie, um dos reformadores, os bibliotecários deveriam ser "agentes a serviço do fomento do saber universal".

O conhecimento é também tematizado por Burke (2002, p.11) em seu estudo sobre a historia social do conhecimento:
Hoje estamos imersos, ao menos segundo alguns sociólogos, em uma "sociedade do conhecimento" ou "sociedade da informação", dominada por especialistas profissionais e seus métodos científicos. Segundo alguns economistas, vivemos em uma "economia da informação", caracterizada pela expansão das atividades relacionadas à produção e difusão do conhecimento. Por outro lado, o conhecimento converteu-se em um problema político de primeira ordem, centrado na questão da informação como bem público ou privado, tratada como mercadoria ou como bem social. Não será nada estranho se os historiadores futuros se referirem ao período em torno do ano 2000 como o da "idade da informação".

Para Garcia Gutiérrez (1999) a área da informação requer abordagem científica de seu itinerário. Deve, nessa medida, aderir ao modelo da complexidade, dizendo não à mera intuição e aos paradigmas tecnicistas nos quais muitas vezes mergulha e se perde. Urge, nesse movimento de re-fundação, redimensionar o papel da tecnologia:

O marco tecnológico é indissociável e indispensável na teoria e nas práticas informacionais, não somente pelos aspectos pragmáticos de ambas, mas também porque sua ausência torna inservível qualquer proposta de ação. A tecnologia é elemento conceitual constitutivo do corpus epistemológico [da Ciência da informação], a tal ponto que, atualmente, não é possível a pesquisa de procedimentos informacionais fora desse quadro (GARCíA GUTIÉRREZ, 1999, p.52) 
Por serem as práticas de informação aspectos indissociáveis da cultura contemporânea, não se pode subestimar o fato de que

a forma da sociedade contemporânea é basicamente tecnológica, o que equivale dizer que a relação do sujeito humano com a realidade passa hoje predominantemente pela tecnologia... Dá-se aqui uma verdadeira mutação antropológica em que se alteram os modos de perceber, a constituição psíquica e as formas lógicas do humano (SODRÉ, 2002, p.96).

No entanto, as práticas de organização são limitantes e limitadas porque, segundo García Gutiérrez (2002, p.13), a área está "historicamente acostumada a resolver esses problemas acumulando escassa bagagem teórica".

Semelhante situação vem sendo enfrentada com sucesso pelas idéias acima referenciadas que superam a idéia ingênua de que a Ciência da Informação é uma disciplina interdisciplinar - junção de várias outras disciplinas, como a Psicologia, a Estatística, a Lingüística etc. - , que visa sobretudo propor respostas práticas a problemas concretos, na ausência, portanto, de quadro teórico-referencial específico.

Inscrita no paradigma da pós-modernidade, a Ciência da Informação instaura seu objeto - a informação - no seu universo simbólico original - distinguindo objeto material - conteúdo documentado - e objeto formal - processos de elaboração de estruturas significantes (formas sintéticas), passíveis de integrarem fluxos sociais e de serem apropriadas subjetivamente. A abordagem do seu objeto é interdisciplinar, já que esta é uma exigência das temáticas que trata, mas a Ciência da Informação enquanto tal constitui campo específico-uma disciplina.

\section{IÊ N CIA D A I N F O R M A ÇÃ O: A L G U M A S Q UESTÕ ES PRO G RA M Á TICAS}

Uma ciência que opera sob as condições expostas acima deve, necessariamente, rever seus fundamentos e sua agenda de pesquisa. Para Barreto (1997), a Ciência da Informação, em particular quando esta enfatiza em suas análises a "tecnologia da informação", impede a elaboração de sínteses que promovam a construção de sua dimensão teórica.

\section{Verifica-se que a maior parte dos nossos cursos de pós-gra- duação é orientada para a análise das questões técnicas relacionadas com o processar, armazenar e recuperar a informa- ção. Considero essa atividade fundamental no processo de geração do saber para a socieda- de, mas de (...) mecanismo inibidor, pela sua própria natu- reza, do pensamento acadêmico (BARRETO, 1997).}

O fascínio pela inovação tecnológica, ou "tentação tecnicista"

\begin{abstract}
é considerar que, à medida em que avança o saber, diminui a distância entre objeto "verdadeiro" e o conhecimento, sendo o real, portanto, presumidamente esgotável pelo conhecimento técnico. Nasce daí uma ideologia teórica, que atribui às bases técnicas em si mesmas o poder de impulsionar a acumulação do capital numa sociedade determinada (SODRÉ, 2002, p.101).
\end{abstract}

Esta crítica ao Programa Sociedade da Informação (Socinfo) cujos objetivos são a expressão de "simulacros cibernéticos" (TAKAHASHI, 2000, p.104), soma-se à opinião de outros pesquisadores que vêem com ceticismo os objetivos de integrar, coordenar e fomentar ações para a utilização de tecnologias da 
informação e comunicação, de forma a contribuir para a inclusão social de todos os brasileiros na nova sociedade e, ao mesmo tempo, contribuir para que a economia do País tenha condições de competir no mercado global (TAKAHASHI, 2000, p.10).

Conhecimento, informação e tecnologias da informação articulam-se como elementos fundamentais de uma Economia do Conhecimento. Conforme Bolaño (19--):

Se podemos chamar esta nova situação de Economia do Conhecimento é porque houve uma mudança radical em relação à forma como o conhecimento científico se incorporava ao processo produtivo no período anterior. Isto pode ser visto ao se analisar a estrutura das cadeias de valor. O caso das bioteconologias é, nesse aspecto, muito similar ao das indústrias culturais, como as da publicação em geral, em que o processo parte de um ato de criação que gera uma matriz a partir da qual se dará a produção em massa das mercadorias que serão distribuídas ao público através da venda direta ao consumir final ou pela intermediação das indústrias.

O que se passa, portanto, como se sabe, na Economia da Comunicação e da Cultura, passa em toda a Economia do Conhecimento. Assim, o trabalho científico, inclusive no que se refere à ciência pura, crescentemente 'market oriented', produz elementos de conhecimento que, se chegam a ter uma aplicação tecnológica, como é o objetivo, levará à produção de uma matriz, como se pode ver, se ficamos no exemplo das biotecnologias, uma nova semente, digamos, um novo medicamento ou um novo procedimento médico.

A esfera de informação encontra-se de tal forma tecnologizada, não sendo incomum confundir os meios das mediações. Sobre este fato, Morin (2000) observou que somente uma posição epistemológica que incorpore a tecnologia como meio, e não como fim, poderá livrar-nos da submissão à tecnosfera.

Além dos aspectos econômicos associados às atividades de informação, não se pode dissociá-las do campo da Cultura, tomado aqui em sentido amplo, já que a informação é elemento constitutivo fundamental do processo de conhecer o mundo. Numa perspectiva teleológica, portanto, cabe à Ciência da Informação pensar e propor modos de organizar o caos informacional próprio das sociedades complexas. Configura-se, portanto, como campo que explica os processos de comunicação nos quais intervém a informação registrada, tornada documento.

A informação é concebida, desse modo, como mensagem inscrita que nasce na sociedade e a ela retorna, o que faz Otlet, aquele que lançou as bases de nosso campo científico, propô-la como disciplina que lida com objetos e fenômenos sociais. Rayward (1994) recorda que uma contribuição importante do documentalista belga assemelha-se aos documentos hipertextuais produzidos nos modernos sistemas de informação. Com efeito, no Traité de 1934, portanto dez anos antes do surgimento das propostas de Bush sobre o Memex, e ao menos trinta e cinco anos de Ted Nelson, Otlet propõe princípios de integração, através de um método padronizado, as informações provindas de diferentes fontes e sob diferentes formas (OTLET; WOUTERS, 1934). Essa proposta ficou conhecida como "princípio monográfico" e, em larga medida, inspira a construção das modernas bases de dados de documentos hipertextuais. 
Os sistemas de informação, enquanto expressões da memória coletiva, operam em distintos espaços, assumindo aspectos contraditórios: a informação é ora bem cultural à qual deve-se garantir acesso universal, ora é produto com valor comercial, alvo de disputas legais para sua proteção e apropriação privada. Sob o paradigma tecnológico, contudo, informação é sinal e mensagem.

Este cenário complexo impõe operações conceituais para a discussão do objeto da Ciência da Informação e a identificação de limites, ou interfaces com outras áreas do conhecimento.

Wersig e Windel (1985) já afirmaram que a Ciência da Informação necessita de uma teoria que balize as "ações de informação". O acesso à informação configura-se como o aspecto central de tais ações. Nessa medida, a Ciência da Informação, ao refletir sobre tais ações, abrese para o diálogo produtivo com as disciplinas que possam, a cada momento e em cada contexto, fornecer conceitos, modelos, métodos. Evita-se, desse modo, a importação irrefletida de conceitos de outras áreas, questão apontada por Wersig (1993), como um dos problemas teóricos a ser enfrentado pela Ciência da Informação.

Pode-se retomar, a partir dessa hipótese, as idéias sobre a interdisciplinaridade, sem cair nas concepções tradicionais veiculadas na bibliografia da área, que, por estarem distanciadas da necessária reflexão sobre o processo histórico que caracteriza um campo do saber, desconhece a identidade disciplinar como condição para o diálogo efetivo com outras disciplinas.

É necessário, também, recuperar a própria história do desenvolvimento da ciência ocidental que, segundo Morin (2001, p.136), é "desde o século XVII, não apenas disciplinar, mas também transdisciplinar". Este último aspecto - a transdisciplinaridade -, é visto por Morin como o princípio da comunicação entre disciplinas, preservando-se o paradigma da complexidade, que se opõe ao da redução/separação, próprio da ciência moderna. Preserva-se a complexidade na medida em que o conhecimento, seja ele, físico ou biológico, se encontre

enraizado numa cultura, numa sociedade, numa história, numa humanidade. A partir daí, cria-se a possibilidade de comunicação entre as ciências, e a ciência transdisciplinar é a que poderá desenvolver-se a partir dessas comunicações, dado que o antropossocial remete ao biológico, que remete ao físico, que remete ao antropossocial (MORIN, 2001, p.139).

Semelhante programa de pesquisa requer também a reflexão sobre o método. Se a ciência moderna baseia-se metodologicamente no princípio cartesiano das idéias simples e claras, uma ciência pós-moderna, cuja característica fundamental é a de adotar como paradigma o princípio da complexidade, deve igualmente buscar novos caminhos para construir-se enquanto saber. Para Morin,

na perspectiva clássica, o método não é mais do que um corpus de receitas, de aplicações quase mecânicas, que visa excluir todo sujeito de seu exercício. O método degrada-se em técnica porque a teoria se tornou um programa. Pelo contrário, na perspectiva complexa, a teoria é engrama, e o método, para ser estabelecido, precisa de estratégia, iniciativa, invenção, arte (MORIN, 2001, p.335).

A adoção de uma nova forma de autonomização, portanto, parece ser mais adequada para o desenvolvimento de um campo do conhecimento que nasce no interior de um movimento de desdogmatização da ciência e de retomada da experiência (SANTOS, 1995, 2000). Nesse sentido, são tarefas da Ciência da informação, 
enquanto campo disciplinar autônomo, delimitar suas fronteiras, constituir sua metalinguagem, desenvolver técnicas apropriadas ao seu objeto, construir modelos, conceitos, teorias. Ao lado disso, é fundamental manter aberto o diálogo com outras disciplinas para renovar continuamente os modos de olhar seu objeto.

Da mesma forma, rever criticamente o processo de sua constituição, ou seja, adotar a perspectiva histórica é um passo não só necessário, mas fundamental para redimensionar o campo. A interdisciplinaridade proposta distancia-se, portanto, da dissolução da Ciência da Informação em campos conexos, tais como a Teoria da informação, as Ciências da Comunicação, as Ciências cognitivas, a Teoria de Sistemas. Ao contrário, propõe-se um percurso que adote simultaneamente a abertura e o fechamento disciplinares, reconhecendo os campos com os quais estabelece relações preferenciais e solidárias.

Acredita-se, por fim, que as relações disciplinares se estabelecem contextualmente, na medida que as ações de informação não se fazem dentro de fronteiras pré-delimitadas. Ao contrário, elas atravessam os campos da atividade humana e, como tais, são condicionadas pelas relações de poder presentes nas formações econômico-sociais ou, como propõe González de Gómez (1996), ancoram-se em "regimes de informação". Ao se aceitar tal formulação, redimensionam-se igualmente os campos nos quais intervêm as ações de informação. Com efeito, as políticas de informação poderão ser interpretadas no quadro dos "regimes de informação" em que se inscrevem.

Uma Ciência da Informação ancorada epistemologicamente no campo das Ciências Sociais aplicadas apresenta, seguramente, a dimensão teórica necessária para ser pensada no interior de regimes de informação. SemeIhante compreensão é por ora incipiente, já que a pesquisa na área gira em torno, fundamen- talmente, da busca de soluções para problemas práticos; não estão delimitadas as fronteiras entre a ação teórica e a ação prática, sua metalinguagem é rudimentar, seus métodos se reduzem à aplicação de receitas. Permanecem, portanto, os desafios: como estabelecer a dimensão teórica como fundamento da prática e a prática como campo de teste de teorias e de emergência de novos problemas teóricos? Como estabelecer relações transdisciplinares ou interdisciplinares entre a Ciência da informação e outros campos do saber sem o risco de sua dissolução?

A discussão epistemológica poderá propor novos espaços de reflexão para os que se dedicam à construção do conhecimento e simultaneamente suscitar a renovação das ações de informação. Por outro lado, o lugar onde se dá a reflexão complexifica-se em razão da emergência das tecnologias da informação (Tis) que operam mudanças radicais em diversos aspectos da vida social. Tais tecnologias afetam de modo particular não só as formas de estabelecer os fluxos de informação, como também, os modos de organizá-la e institucionalizá-la, na medida em que os espaços de interlocução e de construção do conhecimento tornam-se "virtuais" (LÉVY, 1993).

\section{À G UISA DE CONCLUSÃ O: REFU N D A N D O O O B J ETO DA CIÊ NCIA DA IN FOR M A ÇÃ O}

No paradigma da pós-modernidade, como vimos, a Ciência da Informação apresenta o seu objeto substituindo os traços simplificados e fragmentados que o caracterizavam. A compreensão da informação não se dá mais na sua amplitude de fenômeno geral presente em todos os contextos disciplinares, mas na sua complexidade no contexto específico deste domínio.

O conceito de sistema de bens materiais e simbólicos possibilita interpretar, através de um número maior de possibilidades, as questões usualmente propostas em relação aos vários 
fluxos que integram a sociedade. De fato, os problemas podem estar em qualquer elemento da estrutura do sistema de bens e por isso a resposta a eles dependerá simultaneamente do elemento abordado e da estrutura.

No caso específico da informação, pode-se indagar, por exemplo, sobre a sua produção, isto é, se os estoques estão organizados para a sua distribuição ou se o público dispõe de capital simbólico para ativá-los. Pode-se ainda afirmar que existem estoques de informação suficientes, mas que não concretizam fluxos porque não foram organizados para tanto. Pode-se observar também que estoques organizados não cumprem sua função, não por consequência de falha interna, mas porque não participam de processos de distribuição ou não oferecem acesso adequado aos segmentos populacionais a que se dirigem.

Na perspectiva adotada, afirma-se, portanto, que nenhum bem pode ser analisado ao largo do sistema que o institui como tal. Como bem imaterial ou simbólico, a informação projeta um fluxo de relações constantes: na produção, a relação entre o conteúdo registrado e a forma da informação; na disseminação, a relação entre os produtos informacionais e os segmentos de usuários; no acesso, as formas significantes compatíveis simultaneamente com a linguagem do sistema e a linguagem do usuário; na troca, a relação entre o capital cultural dos segmentos populacionais e a forma simbólica do estoque informacional e no uso, a relação entre a informação disponível socialmente e o conhecimento subjetivo dos segmentos sociais. Estas exemplificações evidenciam então que a informação como bem torna-se fluxo através de estruturas relacionais. Então, em nível abstrato a informação é um objeto cuja forma relacional tem duas faces, social e subjetiva, que se complementam.

Como foi afirmado, a Ciência da Informação chama a si a responsabilidade da produção da informação - aspecto social do sistema de bens - elaborando estruturas significantes cada vez mais adequadas para integrar fluxos. Basta observar o avanço experimentado pelas propostas de estruturação de informação e de linguagens documentárias, ontologias e taxonomias, em particular. A construção destas últimas, através de metodologias que integram as linguagens dos documentos, dos usuários e políticas institucionais permite identificar com clareza qual seja o valor social da informação, isto é, o fato de ela poder participar de diferentes estruturas significantes, segundo o segmento de usuários considerados.

Compete portanto à Ciência da Informação estabelecer os princípios e as práticas relacionadas à produção da informação, sua distribuição e formas de acesso. Ela responde também por parte da operação de troca, pois esta etapa se concretiza apenas com a intervenção da moeda de conversão do usuário. Os sistemas de informação podem estar cada vez mais organizados para responder às ações que conferem valor à informação, mas jamais poderão responder isoladamente pela geração do conhecimento. Portanto, a Ciência da Informação tem o papel fundamental não só de responder pelas etapas do processamento social da informação mas também o de promover a idéia de que o conhecimento depende tanto da informação quanto das habilidades e competências integradas em moedas de conversão que permitem interação entre o homem e o sistema de informação no sentido estrito.

A informação, que se apresenta como objeto da Ciência da Informação, é uma estrutura significante que sintetiza os conteúdos dos documentos, sob formas diversas, segundo políticas e segmentos de usuários. Os sistemas de informação são, portanto, criados para o uso humano. O valor da informação consiste, conforme já afirmado, em gerar conhecimento.

Seguindo a proposta aqui desenvolvida, além dos aspectos já apontados anteriormente, 
é oportuno enunciar algumas questões suscitadas pela captura que faz a área da sociedade contemporânea e apontar alguns equívocos nocionais que as sustentam.

Atualmente, sob a denominação "mediação" impõe-se a abordagem dos fluxos de informação com a pretensão de viabilizar contínuas relações entre circulação de informação e produção de conhecimento. Embora seja esta uma ação importante, ao privilegiá-la isoladamente, o campo da Ciência da Informação nega a sua especificidade. Como bem, a informação contempla o seu valor social desde que seja elaborada para tanto. Em larga medida, ao se voltar para práticas de mediação, que não raro são entendidas genericamente, substituem-se os problemas específicos do campo relativos à produção da informação. Se aceito que à Ciência da Informação compete elaborar informação para integrar fluxos sociais, a ela cabe a mediação externa, inscrita nos produtos informacionais. Caso contrário, dissemina-se a idéia de que a presença do mediador neutralizará imperfeições do sistema de informação e de que este exerce apenas uma função patrimonialista.

Outra questão que merece destaque, resultante, possivelmente, da visão mecanicista que exerceu e ainda exerce fascínio na área, diz

\section{REFERÊ N CIAS}

ABRIL, G. Teoria general de la información. Madrid: Cátedra, 1997.

BARRETO, A.A. A questão da informação. São Paulo em Perspectiva, São Paulo, v.8, n.4, p.3-8, 1994.

BARReto, A.A. Perspectivas em Ciência da Informação. Revista de Biblioteconomia de Brasília, Brasília, v.21, n.2, p.155-166, 1997.

BARTHES, R. O rumor da língua. São Paulo: Brasiliense, 1988.

BOLAÑO, C. Impactos sociales y económicos de las tecnologias de la información y comunicación: respeito às clivagens informacionais segundo um recorte social pré-existente - condição profissional, econômica, escolaridade, etc. A importação irrefletida de tais critérios apenas perpetua a distribuição da cultura segundo o recorte tradicional que responde pela desigualdade social. Ao contrário, ao perseguir o valor da informação, a Ciência da Informação deve contemplar o modo pelos quais conteúdos podem ser acessados, manejados e entendidos. O trajeto a ser seguido impõe a busca pela relação fundadora da constituição do sentido: 0 documento, o seu conteúdo, as possibilidades de tratamento e os segmentos variados da população.

Finalizando, é preciso ressaltar que a reboque das seduções da tecnologia, a área tem se calado sobre os modos de recepção que lhes são próprios. Referimo-nos aqui ao uso social dos equipamentos culturais. Com a crescente privatização do consumo da cultura, os rituais coletivos de recepção próprios das bibliotecas e dos museus, por exemplo, tendem a desaparecer. Associada à refundação do conceito de informação, a discussão sobre a expansão e a função dos equipamentos surge como prioridade, mesmo porque eles se constituem instrumentos importantes de inclusão, da democratização da cultura e da cidadania plena.

hipótesis sobre la actual reestructuración capitalista. [s.l.: s.n.], 19_ ].

BURKE, P. Historia social del conocimento: de Gutenberg a Diderot. Madrid: Paidós, 2002. p.11, 80-81. GARCÍA GUTIÉRREZ, A. Aproximación al concepto y al objeto de la información documentación. In: GARCÍA GUTIÉRREZ, A. (Ed.). Introducción a la documentación periodística y informativa. Sevilla: MAD, 1999.

GARCÍA GUTIÉRREZ, A. La memoria subrogada: mediación, cultura y conciencia en la red digital. Granada: Universidad de Granada, 2002. p.13. 
GONZÁLES DE GÓMES, M.N. Da organização do conhecimento às políticas de informação, Informare, Rio de Janeiro, v.2, n.2, p.58-66, 1996.

GUÉROULT, M.M. Le concept d'information dans la science contemporaine. Paris: Gauthiers-Villars/ Les éditions de minuit, 1965.

HARVEY, D. Condição pós-moderna. São Paulo: Loyolla, 1994. p.37.

LÉVY, P. As tecnologias da inteligência: o futuro do pensamento na era da informática. Rio de Janeiro: Ed. 34, 1993.

MACHADO, N.J. Epistemologia e didática. São Paulo: Cortez, 1995. p.193-194.

MORIN, E. Os sete saberes necessários à educação do futuro. São Paulo: Cortez, 2000.

MORIN, E. Ciência com consciência. Rio de Janeiro: Bertrand Brasil, 2001. p.136, 139, 335.

MORIN, E. A cabeça bem feita: repensar a reforma, reformar o pensamento. Rio de Janeiro: Bertrand Russel, 2002. p.16-17.

NONAKA, I.; TAKEUCHI, H. Criação de conhecimento na empresa. Rio de Janeiro: Campus, 1997.

OTLET, P.; WOUTERS, L. Traité de la documentation: le livre sur le livre: théorie et pratique. Bruxeles: Mudaneum, 1934.
PINSKY, J.; PINSKY, C.B. História da Cidadania. São Paulo: Contexto, 2003. p.10.

RAYWARD, W.B. Visions of Xanadu: Paul Otlet (1868-1994) and hypertext. Journal of the American Society for Information Science, v.45, n.4, p.235-250, 1994.

SANTOS, B.S. Introdução a uma ciência pós-moderna. São Paulo: Graal, 1995.

SANTOS, B.S. Para um novo senso comum: a ciência, o direito, a política na transição paradigmática. São Paulo: Cortez, 2000.

SARACEVIC, T. Interdisciplinary nature of information science. Ciência da Informação, Brasília, v.24, n.1, p.36-41, 1995.

SODRÉ, M. Antropológica do espelho: uma teoria da comunicação em rede. Petrópolis: Vozes, 2002. p.101.

TAKAHASHI, T. (Org.). Sociedade da informação no Brasil: livro verde. Brasília: MCT, 2000. 195p.

WERSIG, G. Information science: the study of postmodern knowledge usage. Information Processing and Management, v.29, n.2, p.229-239, 1993.

WERSIG, G.; WINDEL, G. Information science needs a theory of "information actions". Social Science Information Studies, v.5, p.11-23, 1985. 
